\title{
Five-Phase Modular External Rotor PM Machines with Different Rotor Poles: A Comparative Simulation Study
}

\author{
A. S. Abdel-Khalik \\ Electrical Engineering Department, Faculty of Engineering, Alexandria University, Alexandria 21544, Egypt \\ Correspondence should be addressed to A. S. Abdel-Khalik, ayman@spiretronic.com
}

Received 27 April 2012; Accepted 16 July 2012

Academic Editor: Farouk Yalaoui

Copyright () 2012 A. S. Abdel-Khalik. This is an open access article distributed under the Creative Commons Attribution License, which permits unrestricted use, distribution, and reproduction in any medium, provided the original work is properly cited.

The performance of fault-tolerant modular permanent magnet machines depends on the proper selection of the pole and slot numbers which result in negligible coupling between phases. The preferred slot and pole number combinations eliminate the effect of low-order harmonics in the stator magnetomotive force and thereby the vibration and stray loss are reduced. In this paper, three external rotor machines with identical machine dimensions are designed with different slots per phase per pole ratios. A simulation study is carried out using finite element analysis to compare the performance of the three machines in terms of machine torque density, ripple torque, core loss, and machine efficiency. A mathematical model based on the conventional-phasemodel approach is also used for the comparative study. The simulation study is extended to depict machine performance under fault conditions.

\section{Introduction}

Thanks to their high power density, fault tolerant permanent magnet brushless drives have shown promise in critical applications, such as in the electric vehicles (EV), aerospace, and automotive sectors [1]. Multiphase modular permanent magnet machines comprise $m$ magnetically and physically isolated phases, each having one-per-unit inductance which limits the short circuit current to its rated value under fault conditions. Hence, a fault in any phase will not affect others. Many papers address the design and the operating principle of fault-tolerant permanent magnet (PM) machines [2, 3].

These features have made the multiphase modular PM machine a strong candidate in the field of fault tolerant applications [4-6]. Optimum control under healthy and faulted scenarios is proposed to minimize the machine torque ripple $[7,8]$. Favorable slot and pole number combinations for fault-tolerant PM machines have been proposed in [3], which ensure inherently negligible coupling between phases. For a five-phase modular machine, there are three favorable slot and pole number combinations [3], namely, 20 slots/14 poles, 20 slots/ 18 poles, 20 slots/22 poles and their multiples. In [3], the first two combinations are compared in terms of flux distribution and core loss. In
[9], a machine with the second combination is designed by means of the star of slots [10] and using a doublelayer fractional-slot winding. Current control strategies, in case of one-phase or two-phase faults are proposed. An analytical model has been adopted to individuate the most suitable current references, without increasing the motor or inverter cost. In [11]; a comparison between two 5phase PM machine winding configurations is carried out. A new fractional-slot winding, which drastically decreases the cogging torque, is proposed and compared with a classical full-pitched concentrated winding. This method was applied to improve the matching between a naval propulsion fivephase PM machine and its converter. The proposed winding configuration significantly improved torque quality (higher density and lower ripple) and simplified current control without oversizing the electronic components.

In this paper, a complete comparison between the three favorable combinations for five-phase modular machines is carried out in terms of machine torque density, torque ripple, core loss, and overall efficiency. The comparison is based on a simulation study using FEA. Additionally, a mathematical model based on the conventional-phase-model approach [12] is used to corroborate the results. Three machines with an external rotor [13] are designed with the same stator and 


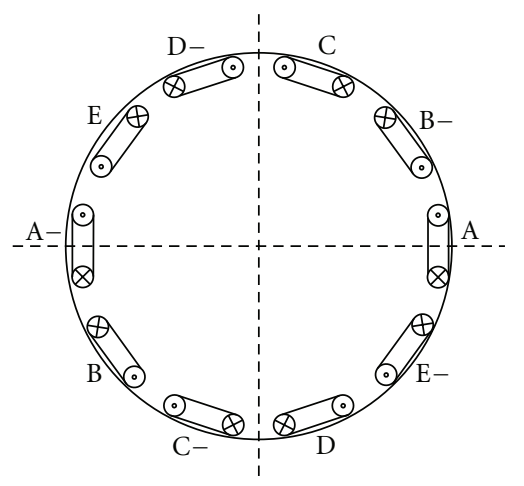

(a)

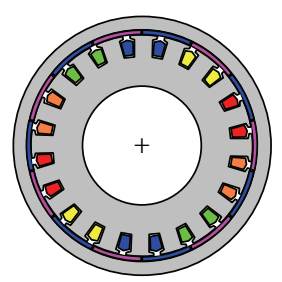

20 slot/14 pole

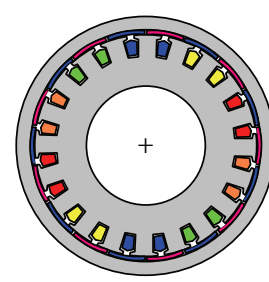

20 slot/18 pole

(b)

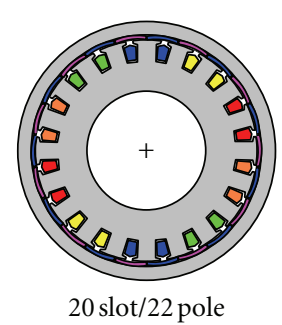

20 slot $/ 22$ pole
FIgURE 1: (a) Stator winding layout and (b) three different designs for modular PM machines with external rotors.

rotor dimensions. The magnet volume is fixed for the various pole number combinations shown in Figure 1. The paper also addresses the performance of the three machines under a one-phase open fault condition. With one phase open, the other phase currents are selected to ensure a zero backward fundamental component [14].

\section{Machine Design}

Three modular PM machines have been designed and modeled using finite element analysis (FEA). The magnets are $\mathrm{NdFeB}$ with $B_{r}=1.1$ Tesla. The stator has five phases, each comprising two coils with 87 turns per coil. The winding configuration from [3] has been used and is shown in Figure 1(a). It is a 20 stator slot single-layer winding. The stator outer diameter, shaft diameter, rotor inner diameter, rotor outer diameter, and stack length are $260 \mathrm{~mm}, 144 \mathrm{~mm}, 272 \mathrm{~mm}, 312 \mathrm{~mm}, 100 \mathrm{~mm}$, respectively. The magnet thickness is $5 \mathrm{~mm}$ and the air gap length is $1 \mathrm{~mm}$. The proposed power rating is $8 \mathrm{~kW}$ at a speed of $240 \mathrm{rpm}$. Figure 1(b) shows the layout of the three machines.

\section{Favorable Slot/Pole Combinations and Corresponding Stator Phase Sequence}

It has been shown in [3] that certain slot and pole number combinations give negligible coupling between phases. For any modular winding with $m$ phases and $S$ slots, the required number of poles is given by (1), and the resulting phase angle between adjacent coils is given by (2);

$$
\begin{aligned}
& 2 p=S\left(1 \pm \frac{n}{2 m}\right), \\
& \theta=2 \pi\left(1 \pm \frac{n}{2 m}\right),
\end{aligned}
$$

where $n=1$, or $n=$ any nonzero odd integer less than $m$, such that $n$ and $m$ do not share any common factors. The variable $n$ is related to the applied phase sequence number as will be shown. For $m=5$, the available values for $n$ will be 1 and 3. Substituting in (1) and assuming that the number of slots is 20 , the corresponding number of poles will be as follows:

(i) for $n=1 \rightarrow 2 p=18$ or 22 and the corresponding angle between phases will be $36^{\circ}$ and $-36^{\circ}$, respectively;

(ii) for $n=3 \rightarrow 2 p=14$ or 26 and the corresponding angle between phases will be $108^{\circ}$ and $-108^{\circ}$, respectively.

To prove the following relations, the stator MMF should be analyzed to investigate the harmonic content of the resulting MMF for a given winding current. For the winding layout shown in Figure 1 [3], the corresponding winding function for any phase is shown in Figure 2(a), and the corresponding harmonic spectrum is shown in Figure 2(b).

For a multiphase system with $m$ phases, the corresponding available current sequences also correspond to $m$. This includes one or two zero-sequence vectors for odd and even numbers of phases, respectively. For a five-phase system, there will be five $(4+1$ zero $)$ available sequences. The fourth sequence is the negative sequence of the first, while the second sequence is the negative sequence of the third. The angle between phase currents in the fundamental sequence is $\alpha=2 \pi / \mathrm{m}$. The stator MMF corresponding to currents with fundamental sequence is shown in Figure 3(a). The corresponding harmonic spectrum is shown in Figure 3(c). The fourth sequence, which corresponds to an angle $4 \alpha$ between phase currents, will give rise to the same flux distribution as the fundamental sequence; however, the MMF wave travels in the reverse direction. For the third sequence, corresponding to an angle $3 \alpha$ between phase currents, the MMF distribution is shown in Figure 3(b), and the corresponding harmonic spectrum is shown in Figure 3(d). The second sequence gives rise to the same flux distribution as the third, with a reverse travelling MMF.

Comparing the two cases, it is evident that the fundamental sequence produces the following space harmonics (3, $7,13,17,23,27$, etc.), while the third harmonic sequence produces the following harmonics $(1,9,11,19,21,29,31$, etc.). Combining the two harmonic spectra will result in all harmonics except the fifth and its multiples $(5,10,15$, etc.). Table 1 summarizes the results obtained up to the 21 st harmonic. The air gap flux densities due to the armature current, without the effect of the rotor magnets, are obtained using FEA for the fundamental and third sequences as shown 


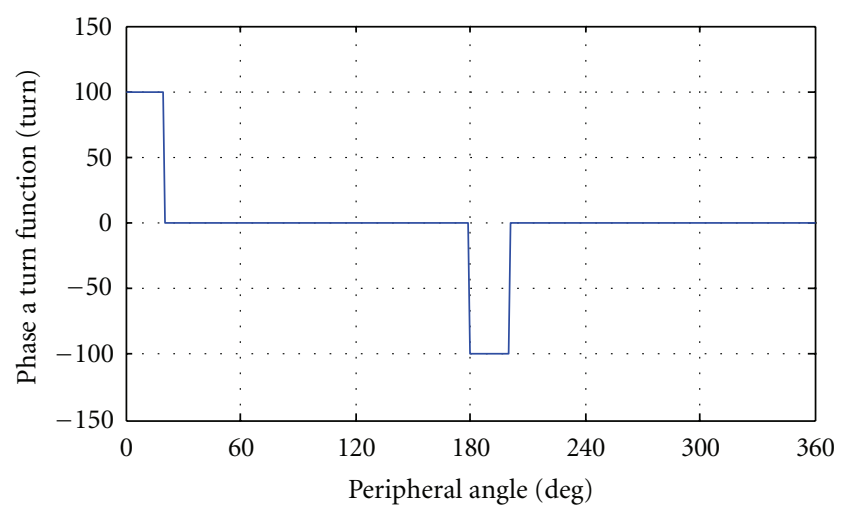

(a)

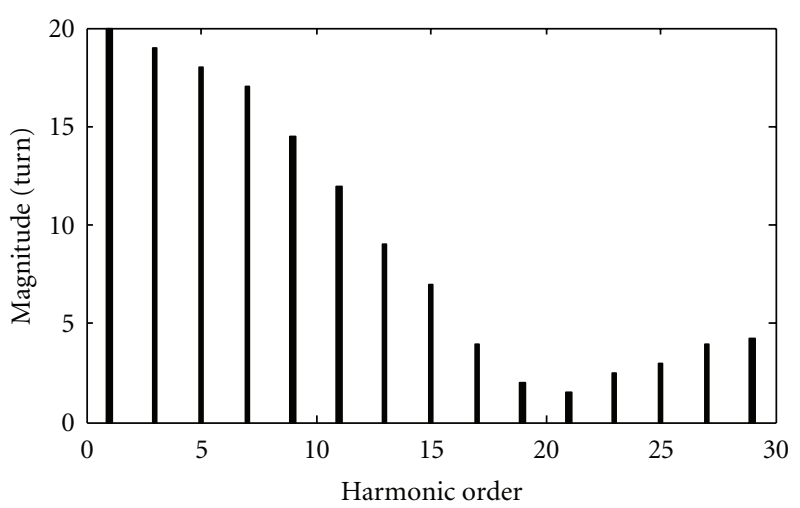

(b)

Figure 2: (a) Phase a turn function and (b) Harmonic Spectrum.

TABLE 1: Relation between different harmonics and the corresponding sequence for a five-phase system.

\begin{tabular}{llllllllll}
\hline $\begin{array}{l}\text { Harmonic } \\
\text { order }\end{array}$ & 1 & 3 & 7 & 9 & 11 & 13 & 17 & 19 & 21 \\
\hline Sequence & 3 & 4 & 1 & 2 & 3 & 4 & 1 & 2 & 3 \\
\hline
\end{tabular}

1 (+ve), 2 (-ve), 3 (+ve), and 4 (-ve).

in Figures 3(e) and 3(f), respectively. The machine flux distribution and the corresponding flux density distribution for both sequences are also shown in Figures 3(g), 3(h), 3(i), and $3(\mathrm{j})$.

\section{FEA Simulation Results}

To obtain a fair comparison, the three machines are simulated at the same rotor speed of $240 \mathrm{rpm}$. For maximum torque per ampere operation, the direct current component is set to zero, while the quadrature component is $30 \mathrm{~A}$. A transient analysis of the three machines was carried out. The resulting torque, core loss, and emf voltage are plotted in Figure 4. Finite element analysis was also used to estimate the machine efficiency by calculating the input power from the phase voltages and phase currents. Table 2 summarizes the main simulation results. It is clear that the machine torque increases as the number of rotor poles increases for the same rms stator current, which, in turn, improves the machine torque density. Moreover, the machine efficiency increases with the increase in rotor poles. However, the required phase voltage, and hence, the corresponding DC link voltage, increases with the number of poles. This is a critical design factor in electric vehicle applications. Although in [3] it was concluded that the 14 pole design has lower core loss, better flux distribution, and eliminates low order armature MMF harmonics, it does not consider the superior advantages of the other combinations, namely, the 20 slot/18 pole and 20 slot/22 pole, which offer higher efficiency and torque density for the same machine volume.
TABle 2: Comparison between the three machines based on FE results.

\begin{tabular}{lccc}
\hline No. of rotor poles & 14 & 18 & 22 \\
\hline Speed (rpm) & 240 & 240 & 240 \\
Frequency $(\mathrm{Hz})$ & 28 & 36 & 44 \\
RMS phase voltage $(\mathrm{V})$ & 97 & 107 & 114 \\
Developed torque $(\mathrm{T})$ & 266 & 332 & 357 \\
Torque ripples $(\Delta \mathrm{T})$ & 40 & 15 & 20 \\
Input power $(\mathrm{W})$ & 8400 & 10080 & 10725 \\
Core loss $(\mathrm{W})$ & 88 & 115 & 133 \\
Developed power $(\mathrm{W})$ & 6685 & 8344 & 8972 \\
Efficiency $(\%)$ & 79.6 & 82.7 & 83.7 \\
Torque per RMS phase current $(\mathrm{Nm} / \mathrm{A})$ & 12.5 & 15.6 & 16.8 \\
\hline
\end{tabular}

\section{Mathematical Model of PM Modular Machines}

A conventional phase model is developed here to represent the five-phase PM modular machine [12] considering fault conditions. The main advantage of mathematical model over the FE model is that the computational time is largely optimized. Moreover, this model can be embedded into a larger control system which will be very difficult with FE simulation. In the phase model, the voltage equations of the machine windings can be written in vector-matrix form as follows:

$$
\begin{gathered}
{\left[V_{s}\right]=\left[R_{s}\right] \cdot\left[I_{s}\right]+\frac{d\left[\lambda_{s}\right]}{d t},} \\
{\left[\lambda_{s}\right]=\left[L_{s}\right] \cdot\left[I_{s}\right]+\left[\lambda_{f}\right],}
\end{gathered}
$$

where $\left[R_{s}\right]=\left[\begin{array}{cccc}R_{s} & & \\ & R_{s} & \\ & & \\ & & R_{s}\end{array}\right]_{n \times n}$ is the resistance matrix, $\left[L_{s}\right]=$ $\left[\begin{array}{cccc}L_{s 11} & L_{m s 12} & \cdots & L_{m s 1 n} \\ L_{m 221} & L_{s 22} & \cdots & L_{m 22 n} \\ L_{m s n 1} & L_{m s n 2} & & L_{s n n}\end{array}\right]_{n \times n}$ is the inductance matrix, $\left[V_{s}\right]$ is the stator phase voltages vector, $\left[I_{s}\right]$ is the stator phase currents vector, $\left[\lambda_{s}\right]$ is the stator flux linkage vector, and $\left[\lambda_{f}\right]$ is 


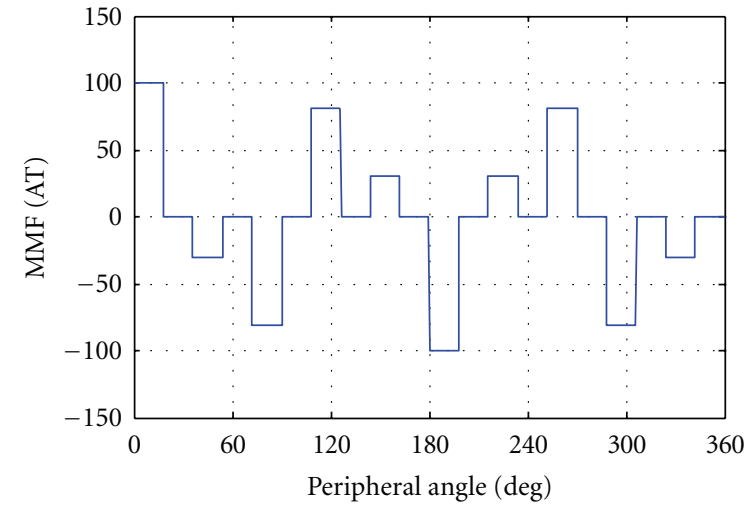

(a)

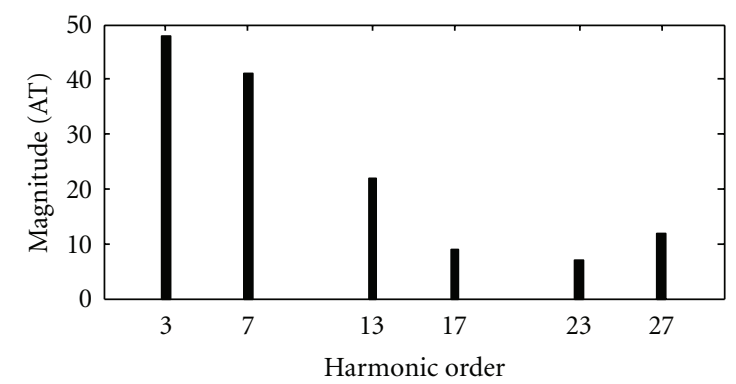

(c)

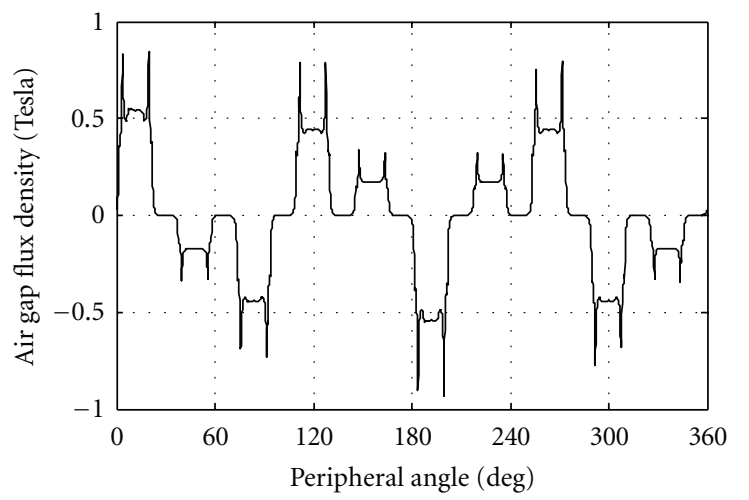

(e)

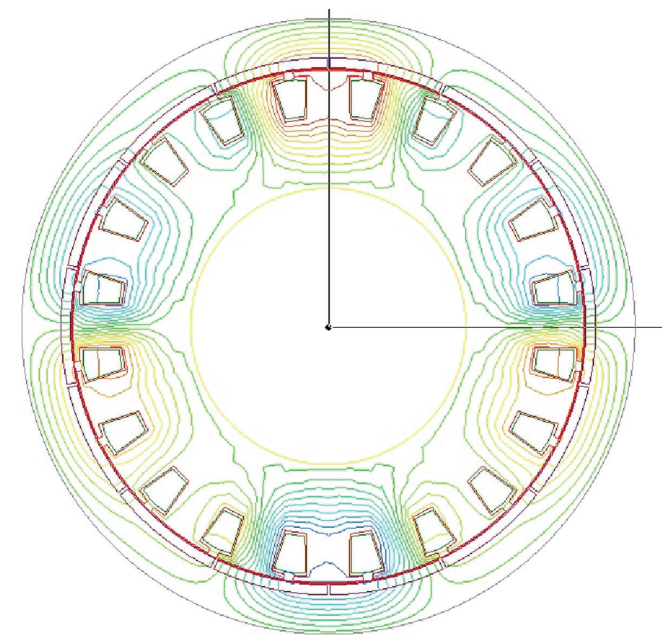

(g)

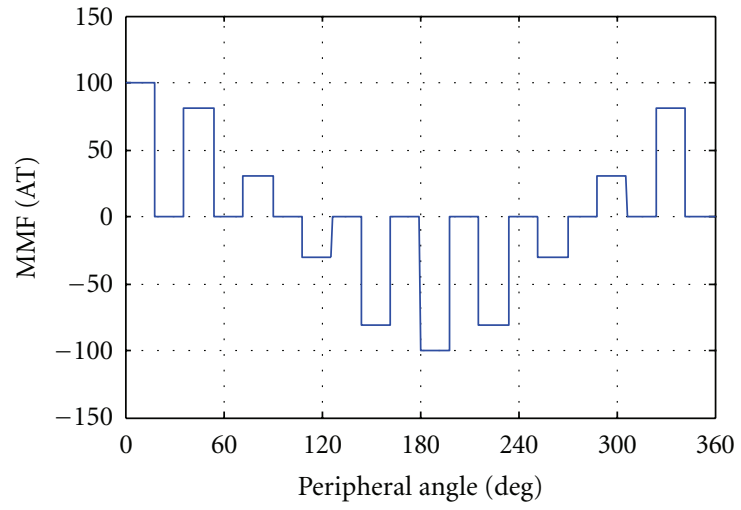

(b)

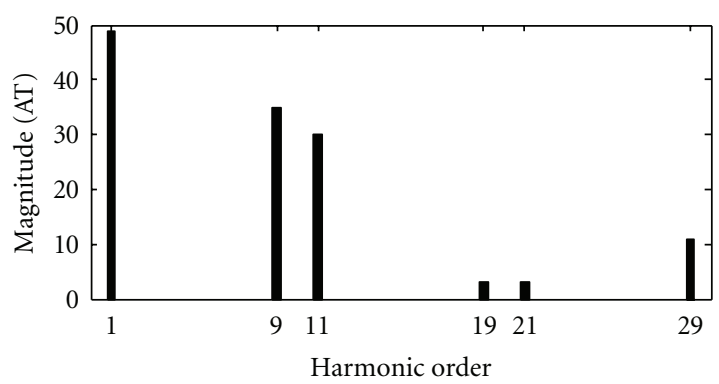

(d)

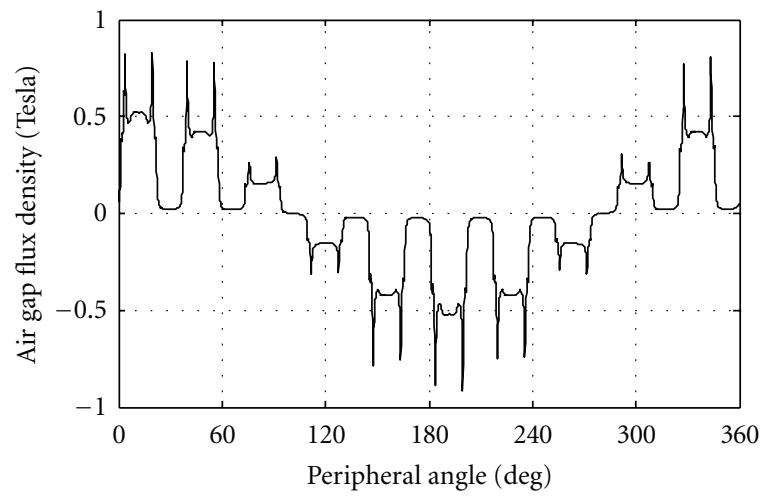

(f)

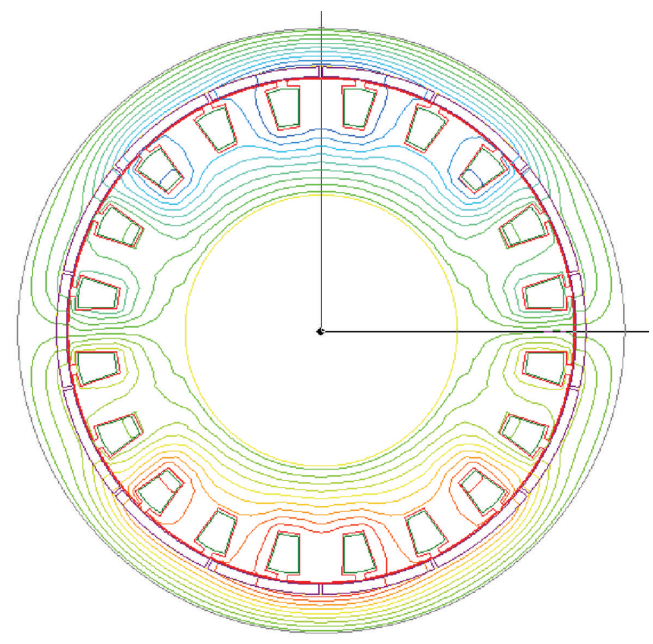

(h)

FIgURe 3: Continued. 


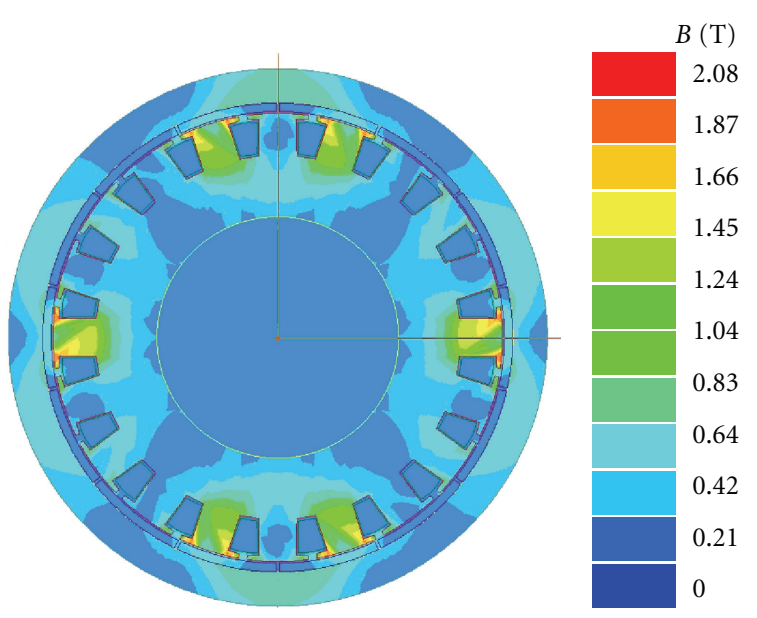

(i)

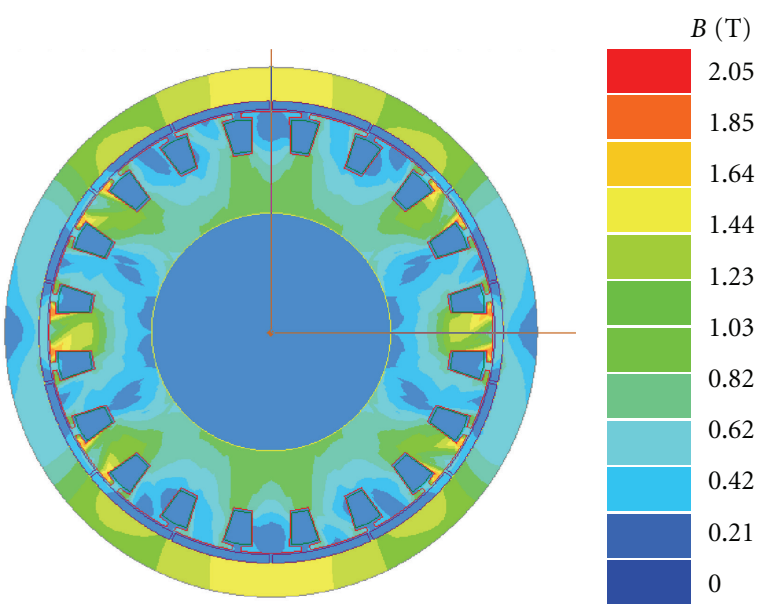

(j)

Figure 3: MMF flux distribution due to different sequences, ( $a, c, e, g$, and i) fundamental sequence, and (b, d, f, h, and j) third sequence. (a and b) MMF using winding function, ( $c$ and d) harmonic spectrum, (e and f) air gap flux using FE, ( $g$ and h) flux distribution, and (i and j) flux density distribution.

the flux linking stator phases due to the rotor permanent magnets (PM). The machine torque is calculated using

$$
T_{e}=\left[I_{s}\right]^{t} \cdot\left[\frac{d \lambda_{s f}\left(\theta_{m}\right)}{d \theta_{m}}\right]
$$

A coil carrying a current of $1 \mathrm{~A}$ represents the rotor permanent magnets. The equivalent number of turns is calculated such that the same flux is produced. Inductances are calculated using the winding function approach [15]. The calculated inductances are the stator self-inductances, and the mutual inductances between the stator windings and the virtual field winding representing the PM effect.

5.1. Winding Function Method. According to winding function theory [15], the mutual inductance between any two arbitrary windings $i$ and $j$ in any electric machine can be computed using

$$
\begin{aligned}
& L_{i j}\left(\theta_{m}\right) \\
& \qquad \quad \mu_{0} \cdot r \cdot l \int_{0}^{2 \pi} g^{-1}\left(\theta_{m}, \phi\right) \cdot N_{i}\left(\theta_{m}, \phi\right) \cdot N_{j}\left(\theta_{m}, \phi\right) \cdot d \phi,
\end{aligned}
$$

where, $\mu_{o}$ is permeability of free space, $r$ is the rotor radius, $l$ is the rotor length, $\theta_{m}$ is the rotor angular position with respect to the stator reference phase $a$ axis, $\phi$ is the angular position along the stator inner surface, $g^{-1}\left(\theta_{m}, \phi\right)$ is the inverse gap function, $N_{i}\left(\theta_{m}, \phi\right)$ is the winding function of winding $i$, and $N_{j}\left(\theta_{m}, \phi\right)$ is the winding function of winding $j$.

The inverse gap function is the reciprocal of the air gap length assuming radial flux and neglecting the effect of iron. Since in modular machines the air gap is approximately uniform, the inverse air gap function is assumed constant.
5.1.1. Winding Function of the Stator Winding. The winding function of a single-layer stator winding with fractional SPP can be derived by plotting the flux distribution produced by phase $a$, calculated using FEA, assuming other phases carry zero current. The flux distribution is shown in Figure 5(a), and the corresponding air gap flux density is shown in Figure 5(b).

5.1.2. Winding Function of the Virtual Field Winding. The winding function of the virtual field winding is shown in Figure 6 . The effective number of turns is found by assuming that this virtual field winding carries $1 \mathrm{~A}$, and equating the flux produced by the PM with the coil flux calculated from

$$
\phi_{\text {pole }}=\frac{N_{\text {eff }} \cdot\left(I_{f}=1\right)}{R_{\text {pole }}},
$$

$R_{\text {pole }}$ is the reluctance of magnetic circuit seen by each pole calculated from (7), and $A_{\text {pole }}$ is the pole area as follows:

$$
\begin{gathered}
R_{\text {pole }}=\frac{g_{o}}{\mu_{0} A_{\text {pole }}}, \\
A_{\text {pole }}=\frac{2 \pi R}{2 p} L .
\end{gathered}
$$

5.2. Inductance Calculation. The inductance of different windings can be calculated by substituting by the winding function of different windings into (5). The stator inductances can be evaluated as follows:

$$
L_{a a}=L_{b b}=L_{c c}=2 \frac{\mu_{0} R l}{g} N_{1}^{2} \beta, \quad L_{a b}=L_{b c}=0,
$$

where, $\beta$ is the coil span (for this example it equals $\pi / 10$ ). Since the mutual inductance between phases is zero, 


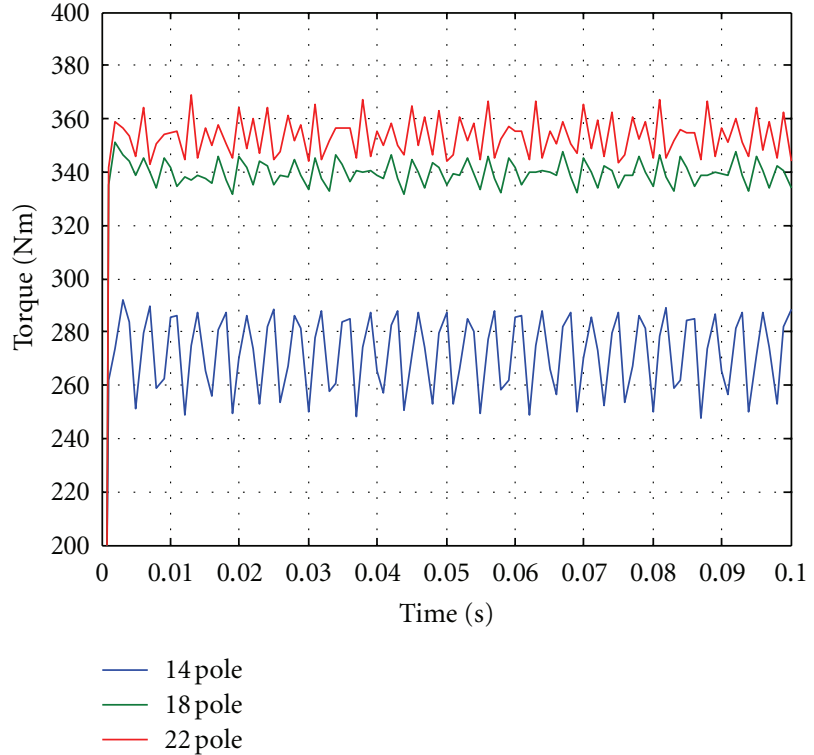

(a)

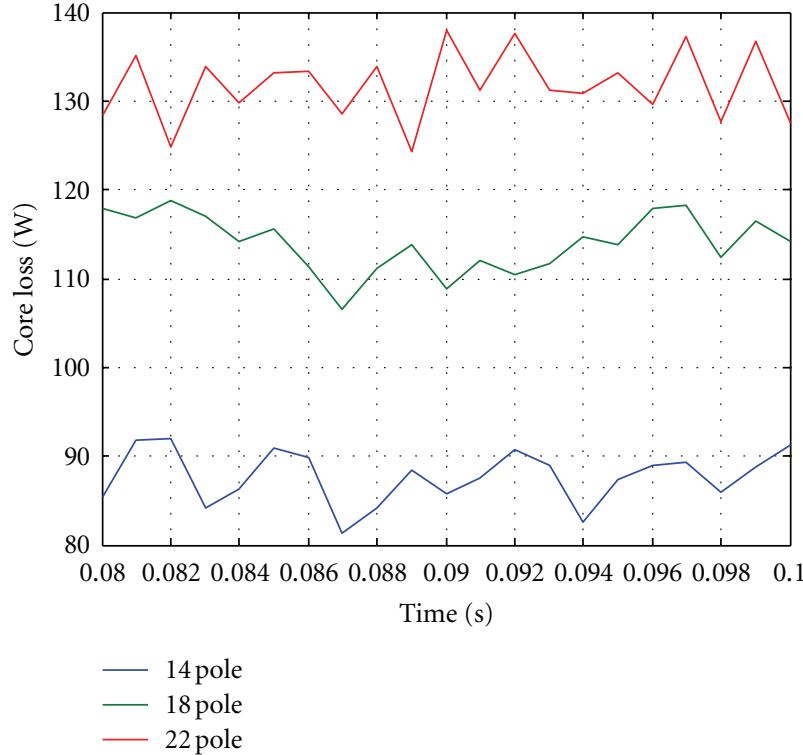

(b)

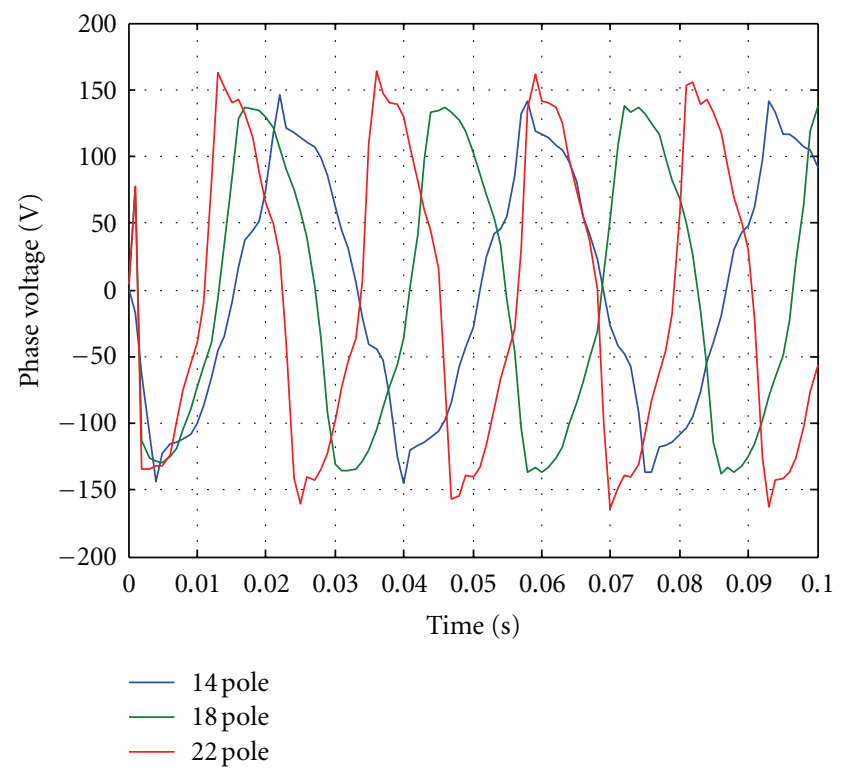

(c)

FIgure 4: (a) Machine torque, (b) core loss, and (c) phase voltage.

the direct axis inductance is equal to the phase inductance given by (9).

$$
L_{d}=2 \frac{\mu_{0} R l}{g} N_{1}^{2} \beta
$$

The mutual inductance between the stator winding and the virtual field winding will vary sinusoidally with rotor angle $\theta$ if the space harmonics are neglected. However, the actual variation has an approximate trapezoidal wave shape. A plot of the corresponding flux linkage for a virtual field current of $1 \mathrm{~A}$ is shown in Figure 7(a), while its derivative with respect to position is shown in Figure 7(b).
The machine's time domain simulation model is shown in Figures 8(a) and 8(b), while the controller's block diagram is shown in Figure 8(c). As previously mentioned, a fivephase winding has 4 different possible sequences, two of them are forward, and two of them are backward sequences. Based on the MMF distributions, the first sequence is applied to the 20 slot/ 14 pole machine, while the second sequence is applied to the 20 slot/ 18 pole machine. The third sequence is applied to the 20 slot $/ 22$ pole machine, and the forth sequence can be used to drive the 20 slot/14 pole machine backward. Also, swapping the 2nd and 3rd sequences for 20 slot $/ 18$ pole and 20 slot $/ 22$ pole machine cases can be used to reverse the machine direction. The direct 


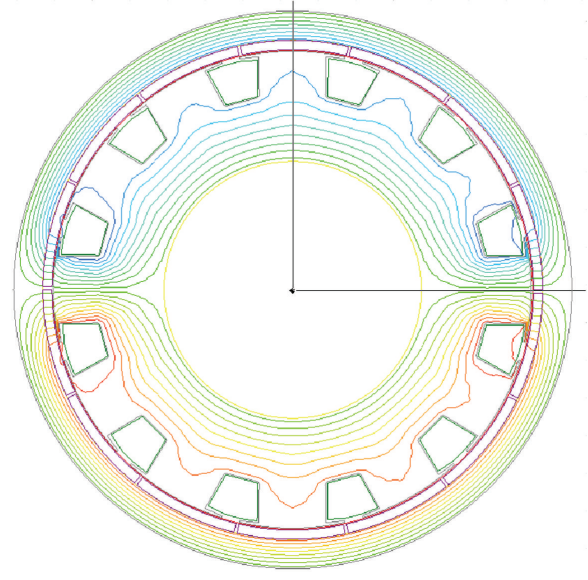

(a)

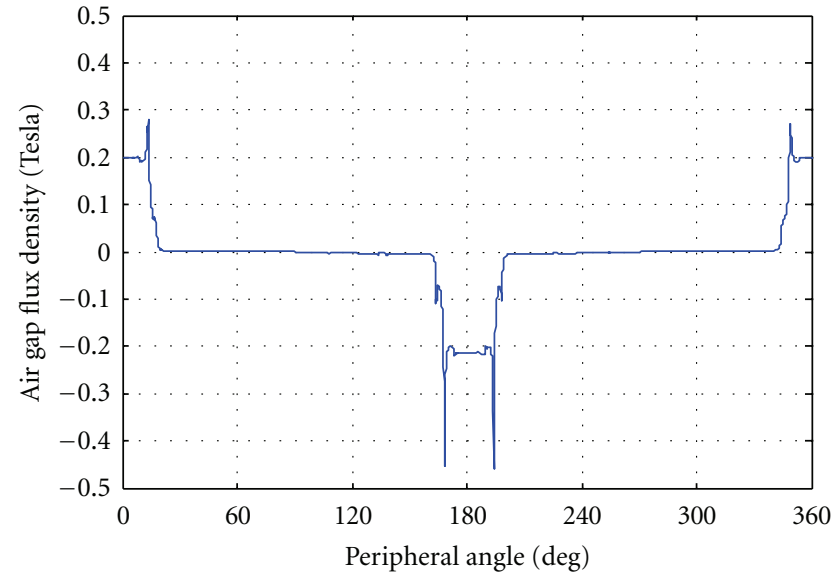

(b)

Figure 5: Flux produced by one stator phase using FEA, (a) flux distribution and (b) air gap flux density.

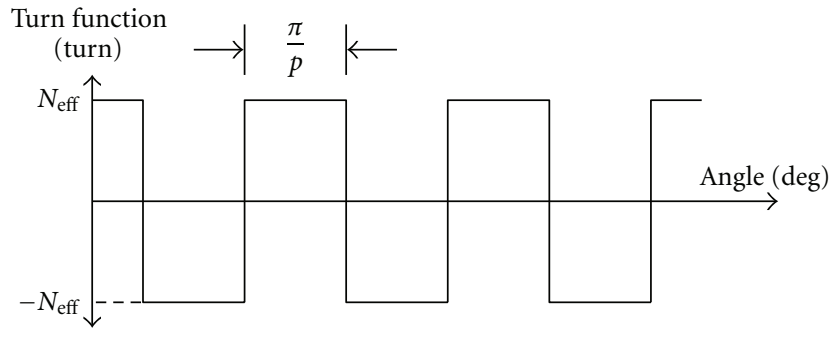

FIGURE 6: Winding function of the virtual field winding.

axis current components for both fundamental and third planes are set to zero. The quadrature current component for the fundamental is derived from the speed error using a PI controller, while that of the third is set to zero. The machine is simulated at a constant speed of 240 RPM. The transformation matrix that converts the dq command values to the corresponding phase values is given by

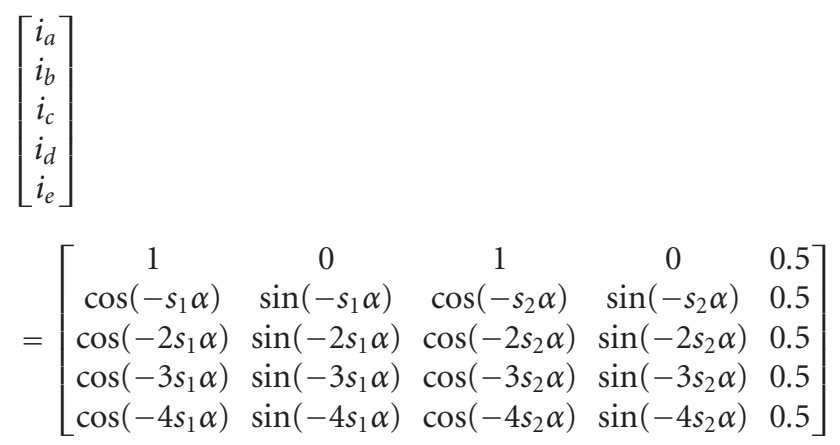

$$
\cdot\left[\begin{array}{c}
i_{d 1} \\
i_{q 1} \\
i_{d 3} \\
i_{q 3} \\
i_{0}
\end{array}\right],
$$

where $\alpha=2 \pi / 5$, and $s_{1}$ and $s_{2}$ are the sequence order.
The constants $s_{1}$ and $s_{2}$ depend on the number of rotor poles. This is because each value of rotor pole corresponds to a specific stator MMF harmonic with a given phase sequence. The values of $s_{1}$ and $s_{2}$ are given in Table 3. Harmonic injection is possible with modular machine designs if the magnets give a quasi-rectangular spatial flux distribution [4]. In this design, FE results show that the third harmonic component in the induced voltage is small. This makes the torque enhancement by stator current higher-order harmonic injection of negligible effect. Hence, the reference values for the third harmonic sequence are set to zero, as shown in the controller block diagram shown in Figure 8(c). The controller is based on conventional vector control of PM machines. Based on the machine speed error, a PI controller is used to decide the required quadrature component for the fundamental sequence plane. Unless field weakening is employed, the direct axis component is set to zero. The machine phase currents are measured and transformed to their sequence values. Four PI controllers are then used to obtain the required sequence voltage components, from which different machine phase voltages are calculated.

Figure 9(a) illustrates the machine speed, torque, phase currents, and phase voltages, for different numbers of rotor poles. In this case, the machine is accelerated at no load in $0.05 \mathrm{~s}$ to a speed of $240 \mathrm{rpm}$, then a $300 \mathrm{Nm}$ load is applied at $0.1 \mathrm{~s}$. It is evident that the 20 slot/ 18 pole machine has the lowest torque ripple. Moreover, the rms phase current decreases as the number of rotor poles increases. Finally, the rms stator phase voltage increases as the number of rotor poles increases. A comparison between phase currents and phase voltages for different numbers of rotor poles are shown in Figures 9(b) and 9(c), respectively. The machine performance indices are summarized in Table 4. It is evident from Table 4 that the machine torque per RMS current and efficiency improve with the increase in number of poles. However, the required DC link voltage increases with the increase in rotor poles, due to the increase in required phase voltage.

As general conclusions derived from simulation results, while the 20 slot/22 pole selection gives better efficacy, 


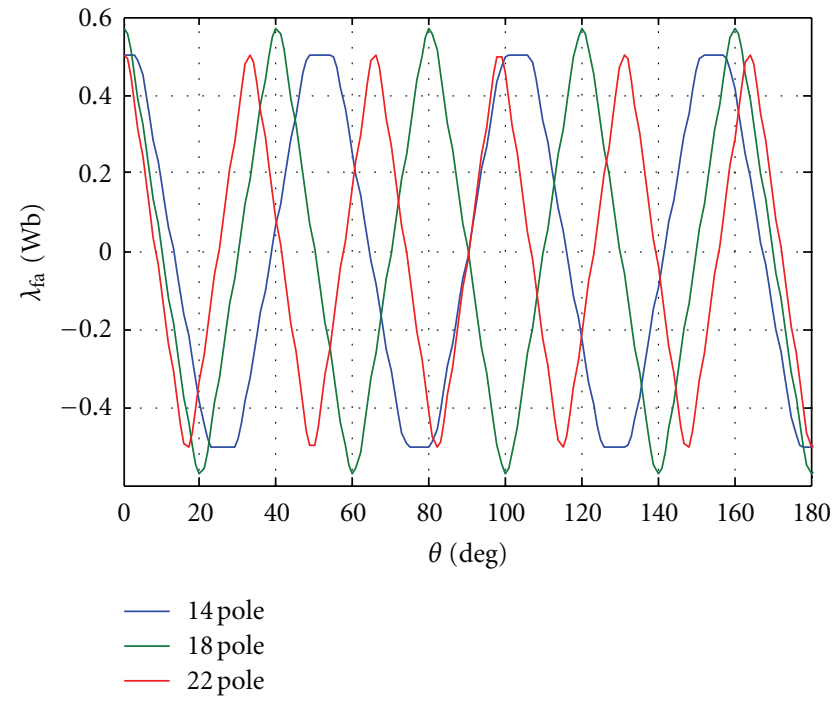

(a)

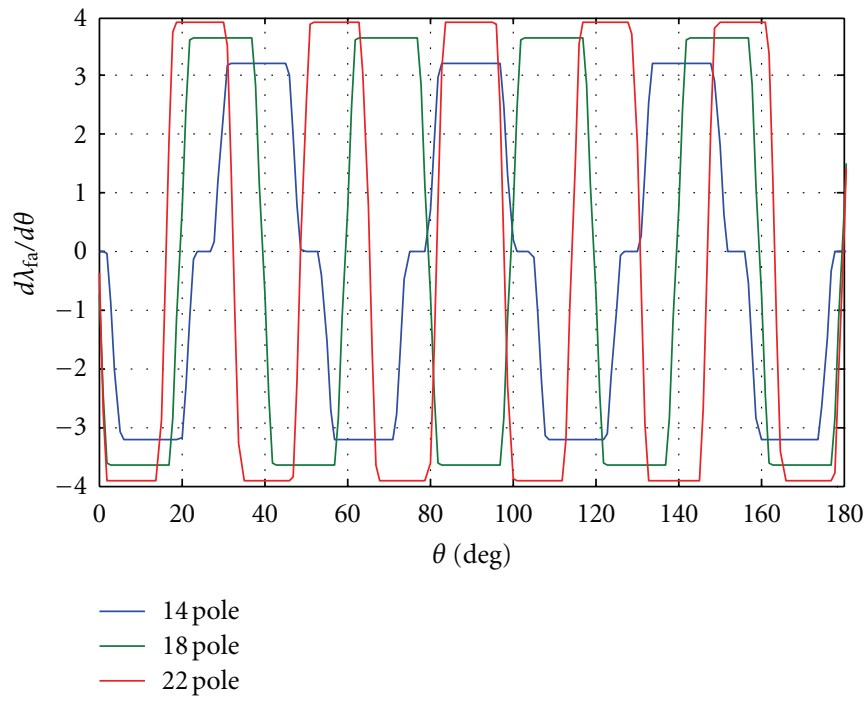

(b)

Figure 7: (a) Phase a flux linkage due to PM and (b) flux linkage derivative with respect to rotor angle.

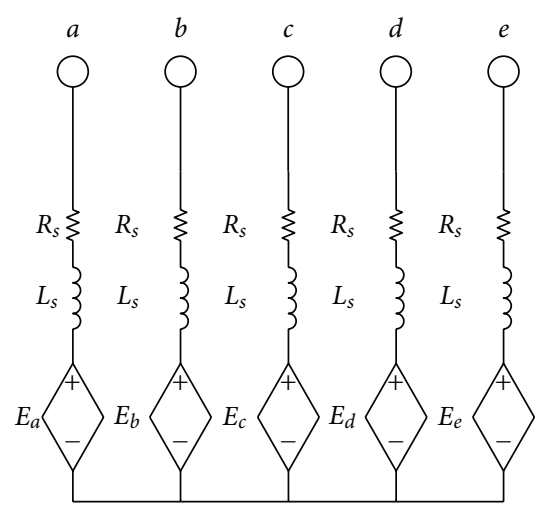

(a)

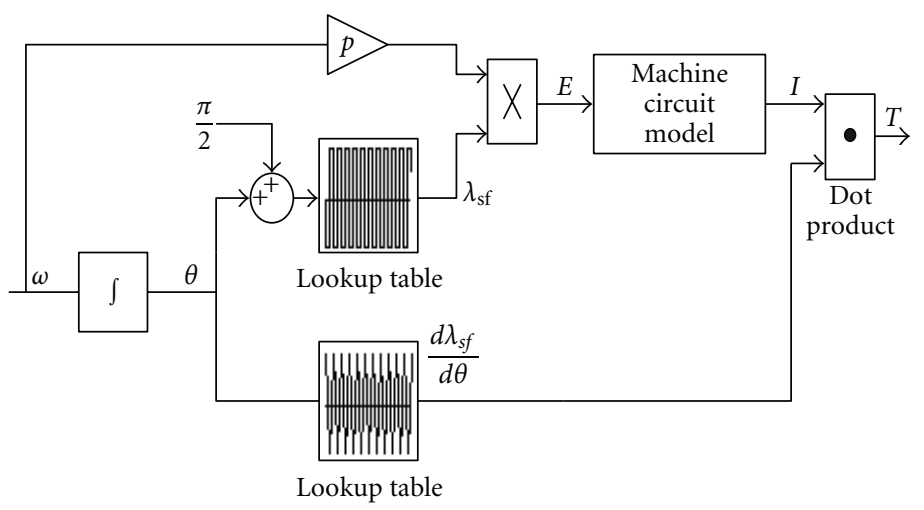

(b)

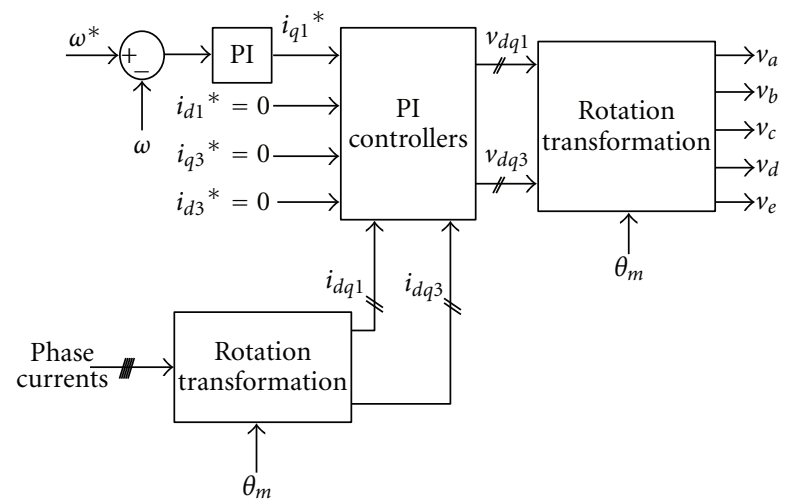

(c)

FIGURE 8: Simulation model, (a) machine model, (b) equivalent stator circuit model, and (c) controller.

TABLE 3: Relation between number of poles and sequence number.

\begin{tabular}{lccc}
\hline Number of rotor poles & 14 & 18 & 22 \\
\hline Value of $s_{1}$ & 1 & 2 & 3 \\
Value of $s_{2}$ & 2 & 1 & 4 \\
\hline
\end{tabular}



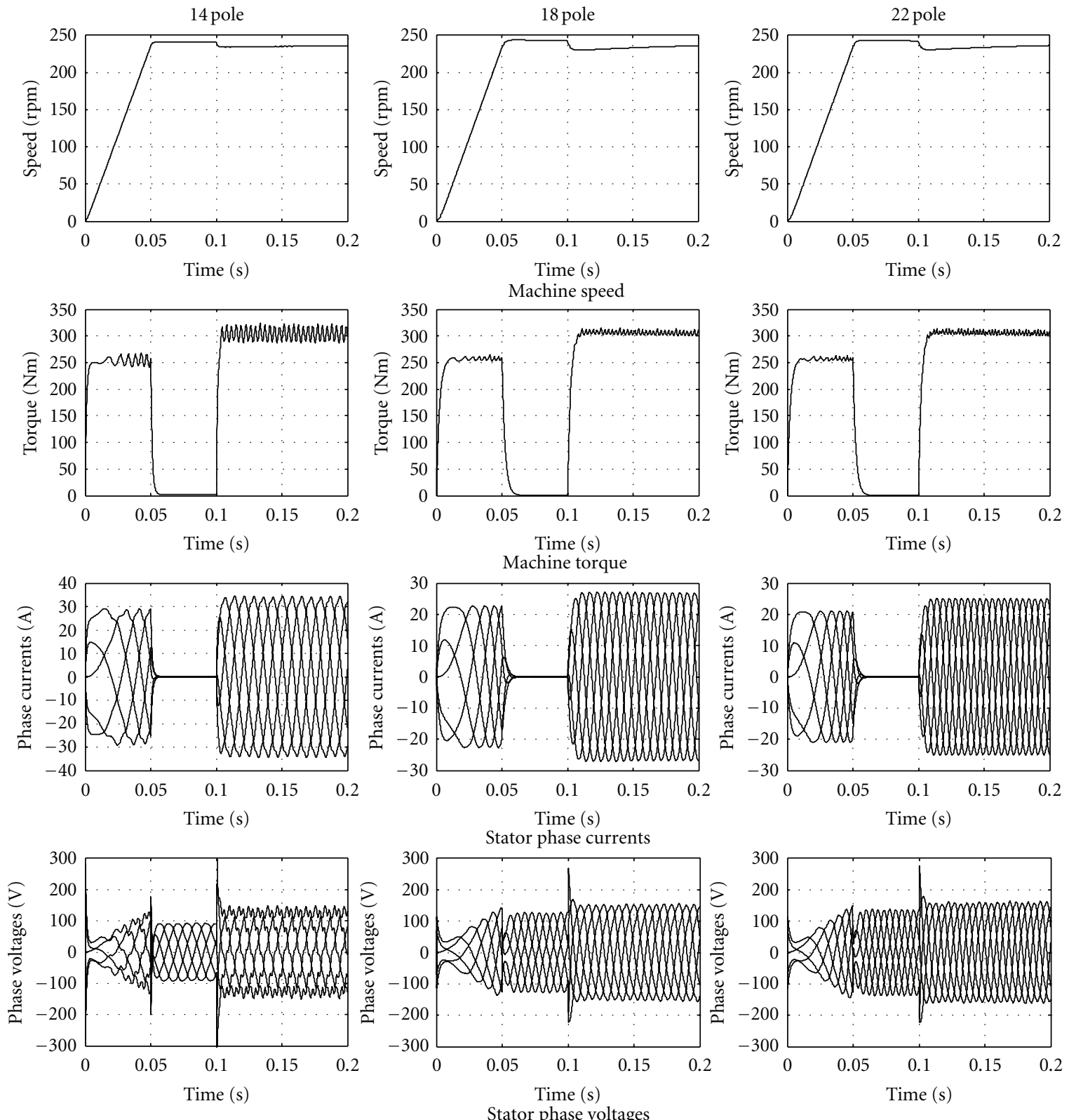

(a)
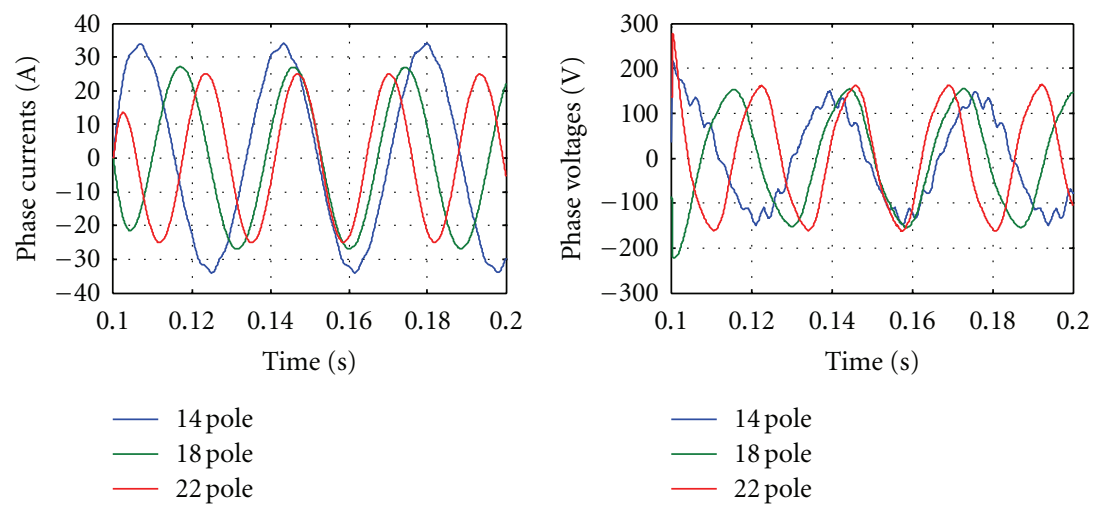

(b)

(c)

FIGURE 9: (a) Machine response with different number of poles, (b) comparison between phase currents, and (c) comparison between phase voltages for different rotor pole number. 


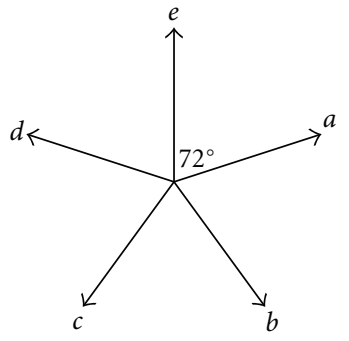

(a)

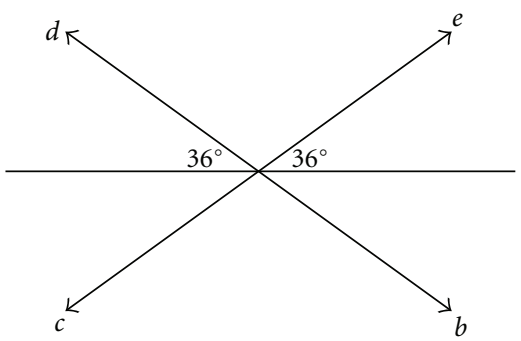

(b)

FIgURE 10: Current phasor diagram: (a) healthy mode operation and (b) one phase open.

TABLE 4: Machine performance indices for different number of rotor poles.

\begin{tabular}{lccc}
\hline Number of rotor poles & 14 & 18 & 22 \\
\hline Speed $(\mathrm{rpm})$ & 240 & 240 & 36 \\
Frequency (Hz) & 28 & 107 & 44 \\
RMS phase voltage (V) & 97 & 19.1 & 114 \\
RMS phase current (A) & 23.5 & 300 & 17.6 \\
Load torque (Nm) & 300 & 10 & 300 \\
Torque ripples $(\Delta \mathrm{T})$ & 30 & 7543 & 12 \\
Load power $(\mathrm{W})$ & 7543 & 115 & 7543 \\
Core loss $(\mathrm{W})$ & 88 & 8948 & 133 \\
Input power $(\mathrm{W})$ & 9562 & 84.3 & 8697 \\
Efficiency $(\%)$ & 78.8 & 15.7 & 86.7 \\
Torque per rms current (Nm/A) & 12.77 & 17.05 \\
\hline
\end{tabular}

the 20 slot/18 pole selection corresponds to minimum torque ripple and the 20 slot/14 pole selection requires less DC-link voltage for the same machine speed. Hence, the optimum selection is mainly application dependent.

\section{Fault Tolerant Applications}

Multiphase machines have promising fault tolerant capabilities because they present additional degrees of freedom and can steadily operate with one or two phases open [11]. When one or two phases are open, due to a device failure or a fault in the phase windings, a forward rotating field can be still obtained by modifying the currents in the healthy phases to ensure some constraints, namely, the same output torque and minimum copper loss $[12,14]$. In this paper, the condition of one phase open is considered.

6.1. Optimum Phase Currents for One Phase Open. When one phase is open due to a device failure or a fault in the phase windings, a forward rotating field can be still obtained by setting the currents in the faulted phase to zero, and keeping the MMF and torque unchanged. During the fault conditions, a new set of currents for the healthy phases is applied [16-18]. The current control strategies are chosen so as to obtain no zero-sequence current $\left(\sum i=0\right)$, and a reasonable average torque.

If phase $a$ is open, the current $i_{a}$ is zero and the currents in the remaining phases should satisfy the condition in (12), also illustrated in Figure 10

$$
i_{b}=-i_{d}, \quad i_{c}=-i_{e} .
$$

To maintain an undisturbed rotating MMF in a fivephase machine with one phase open, the fundamental current amplitude of the healthy phases should increase by 1.38 times the value when all five phases are functional [18].

Consider the $i_{d}$ and $i_{q}$ axes currents corresponding to the torque and flux producing components. The current commands for the remaining four phases are the following:

$$
\left[\begin{array}{l}
i_{x} \\
i_{y} \\
i_{z} \\
i_{w}
\end{array}\right]=1.38 \cdot\left(\begin{array}{cc}
\cos \left(\omega t-\frac{\pi}{5}\right) & \sin \left(\omega t-\frac{\pi}{5}\right) \\
\cos \left(\omega t-\frac{4 \pi}{5}\right) & \sin \left(\omega t-\frac{4 \pi}{5}\right) \\
\cos \left(\omega t+\frac{4 \pi}{5}\right) & \sin \left(\omega t+\frac{4 \pi}{5}\right) \\
\cos \left(\omega t+\frac{\pi}{5}\right) & \sin \left(\omega t+\frac{\pi}{5}\right)
\end{array}\right) \cdot\left[\begin{array}{c}
i_{d} \\
i_{q}
\end{array}\right] .
$$

The phase currents' commands are labelled with subscripts $x$, $y, z$, and $w$. The relation between the actual reference current and these four currents will depend on the number of rotor poles, because the current sequence should be adapted to the corresponding number of rotor poles, as given in Table 5. 

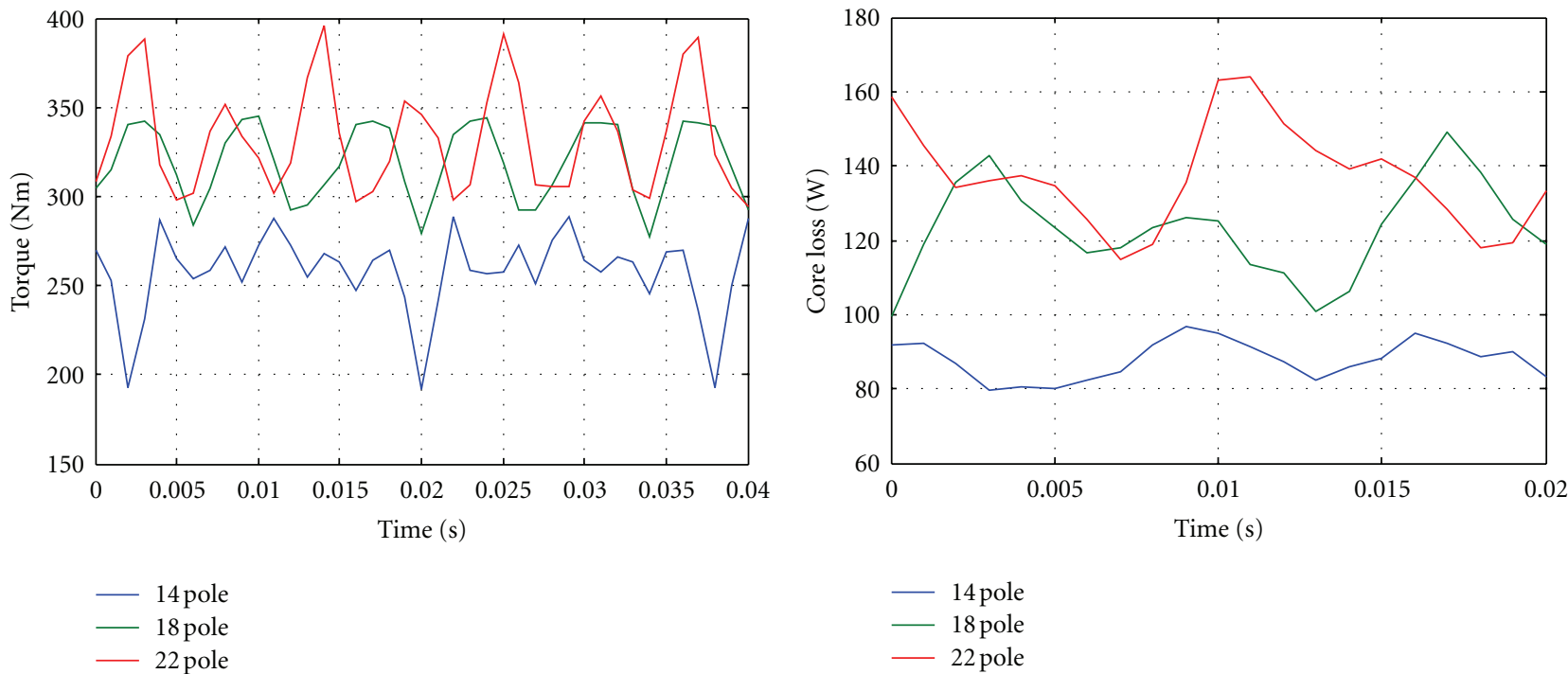

(a)

(b)
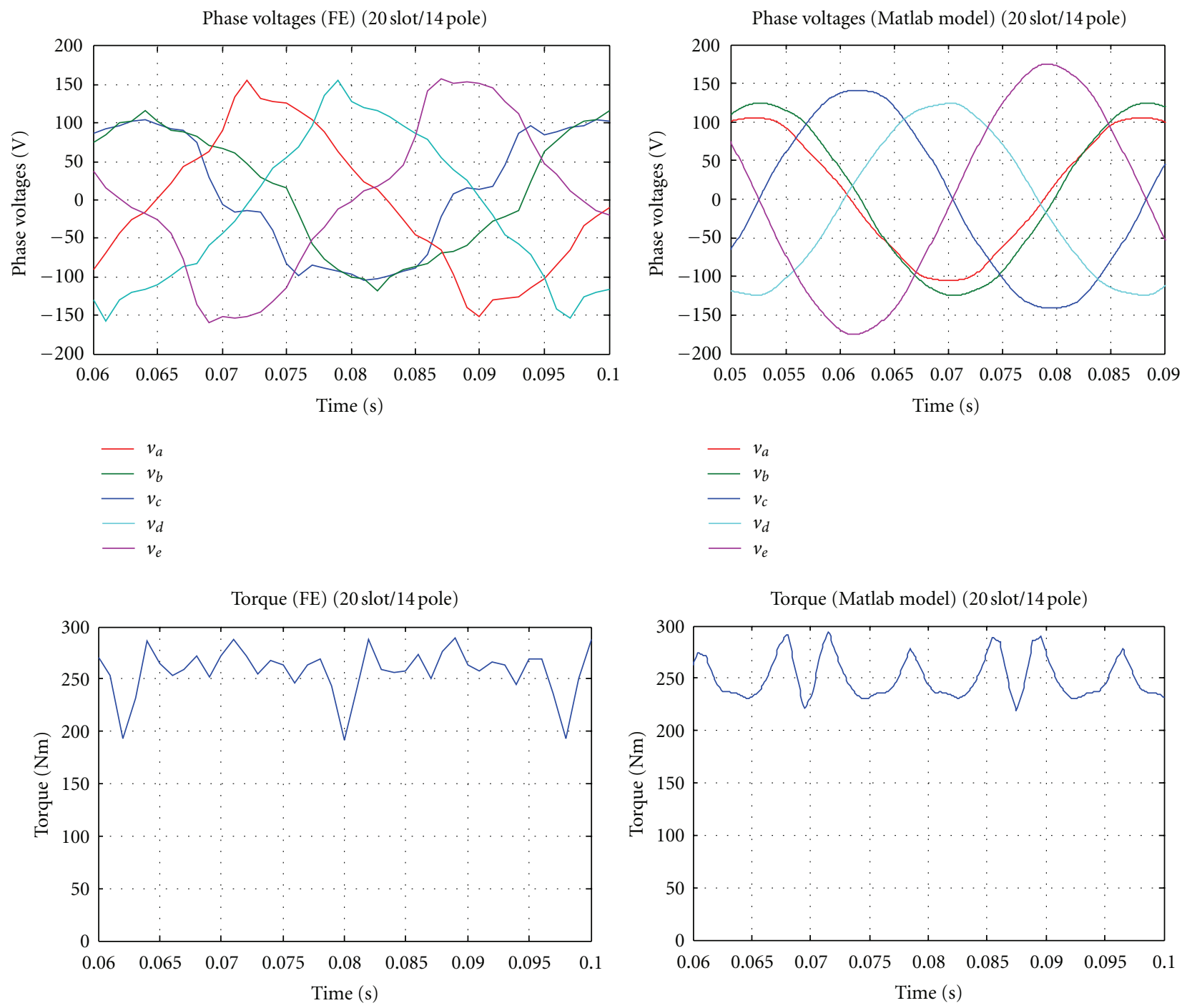

(c)

Figure 11: Continued. 

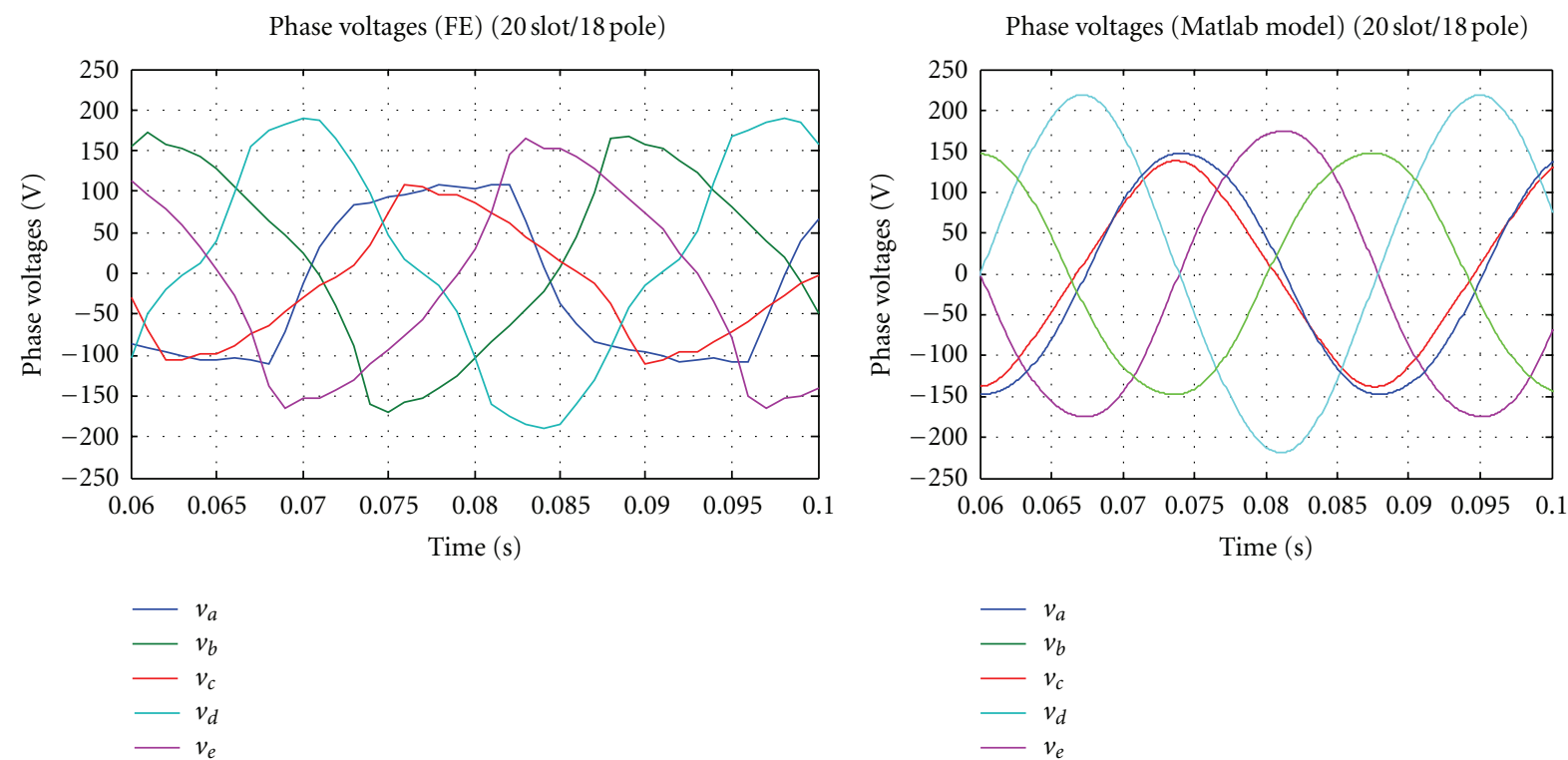

$$
\begin{array}{ll}
- & v_{a} \\
- & v_{b} \\
- & v_{c} \\
- & v_{d} \\
- & v_{e}
\end{array}
$$

Torque (FE) (20 slot/18 pole)

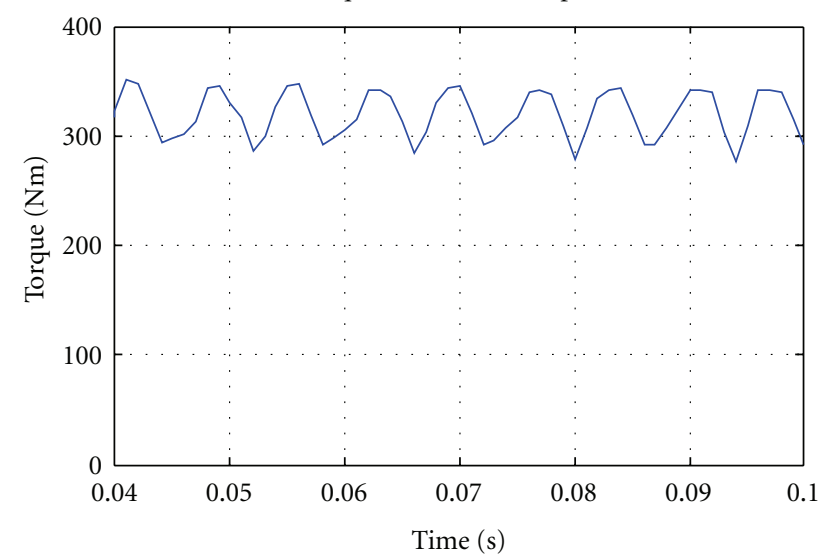

Torque (Matlab model) (20 slot/18 pole)

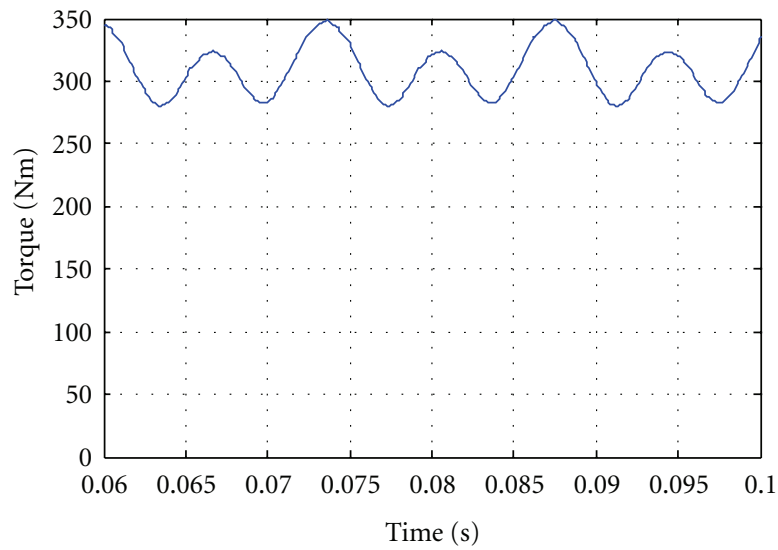

(d)

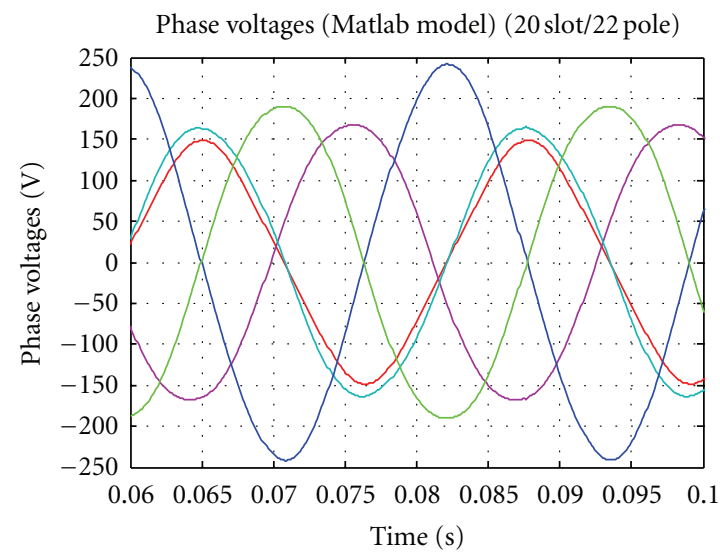

$-v_{a}$
$-v_{b}$
$-v_{c}$
$-v_{d}$
$-v_{e}$

(e continue)

Figure 11: Continued. 

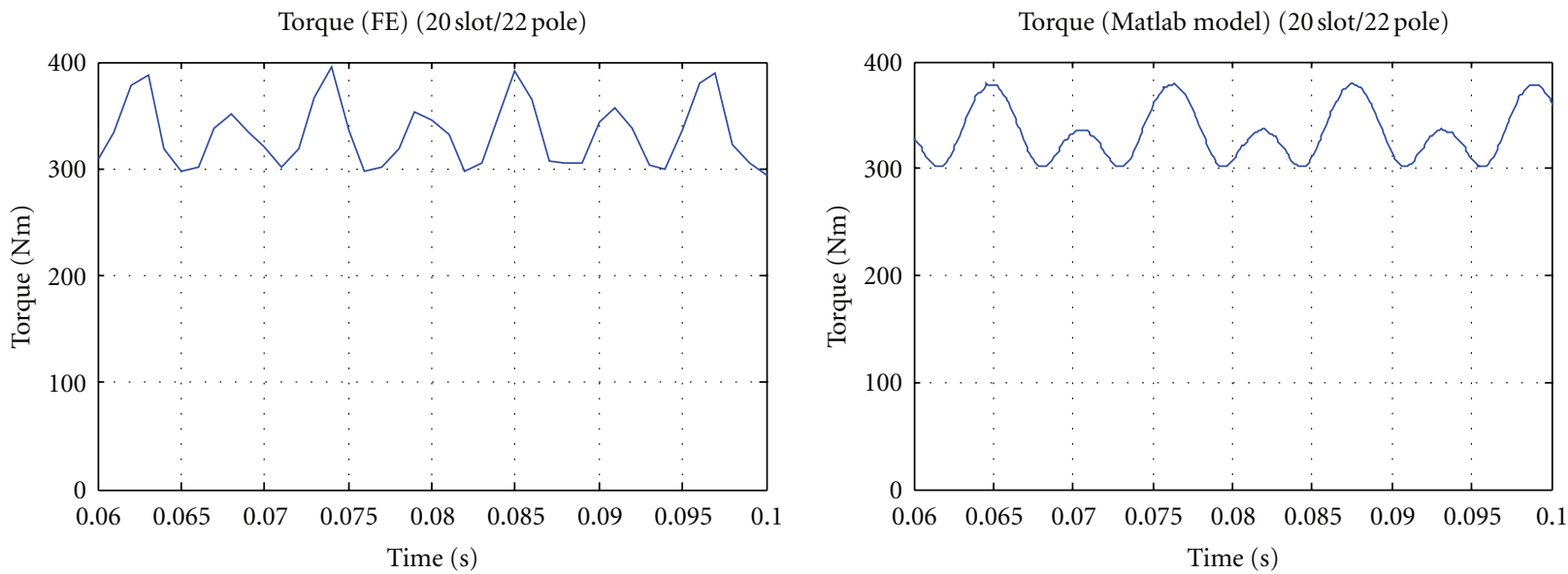

(e)

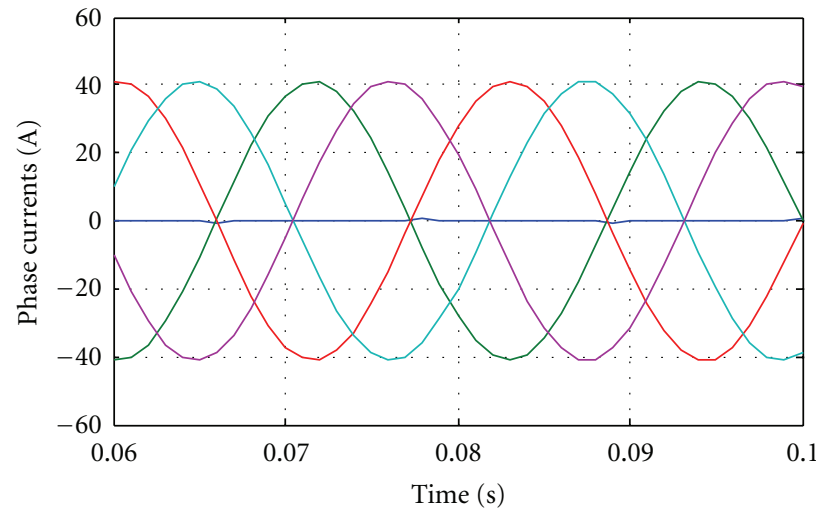

$$
\begin{array}{r}
-I_{a} \\
-I_{b} \\
-I_{c} \\
-I_{d} \\
-I_{e}
\end{array}
$$

(f)

\begin{tabular}{|c|c|c|c|c|c|c|c|}
\hline Number of rotor poles & \multicolumn{2}{|l|}{14} & \multicolumn{2}{|c|}{18} & \multicolumn{3}{|c|}{22} \\
\hline \multirow{5}{*}{ Phase currents and command currents relationship } & {$\left[i_{a}\right]$} & {$[0]$} & {$\left[i_{a}\right]$} & {$[0]$} & $i_{a}{ }^{-}$ & & $0]$ \\
\hline & $i_{b}$ & $i_{x}$ & $i_{b}$ & $i_{y}$ & $i_{b}$ & & $i_{z}$ \\
\hline & $i_{c}=$ & $i_{y}$ & $i_{c}=$ & $i_{w}$ & $i_{c}$ & $=$ & $i_{x}$ \\
\hline & $i_{d}$ & $i_{z}$ & $i_{d}$ & $i_{x}$ & $i_{d}$ & & $i_{w}$ \\
\hline & {$\left[i_{e}\right.$} & $\left\lfloor i_{w}\right\rfloor$ & $\left\lfloor i_{e}\right\rfloor$ & $\left.i_{z}\right\rfloor$ & $i_{e_{e}}$ & & $\left.-i_{y}\right\rfloor$ \\
\hline Sequence & \multicolumn{2}{|c|}{ Fundamental } & \multicolumn{2}{|c|}{ Second sequence } & \multicolumn{3}{|c|}{ Third sequence } \\
\hline
\end{tabular}

FIgURE 11: Machine performance with one phase open, (a) developed torque and (b) core loss for the three machines. Phase voltages and developed torque for (c) 20 slot/14 pole machine, (d) 20 slot/18 pole machine, and (e) 20 slot/22 pole machine (f). Reference currents with one phase open.

TABLE 5: Relation between phase currents and command currents.

6.2. Simulation Results. In this section, the simulation results for the modular machine with one phase open and different numbers of rotor poles are carried out using both FEA and mathematical model in Matlab/Simulink. Figure 11 shows the simulation results for the three selections. Comparing the simulation results for the three motors, similar conclusions, as in the healthy case, will be obtained. It is evident that the 18 pole selection gives lower torque ripple than the other selections in the case of one phase open and it will be more suitable for applications that require smooth developed torque. On the other hand, as the number of rotor poles increases, the magnitude of the corresponding phase voltages increases. This makes the 14 pole selection a better selection to limit the required DC-link voltage. Finally, the 22 pole 
will correspond to higher average torque and, consequently, better machine torque density but with a relatively higher torque ripples.

\section{Conclusion}

This paper presents a comparison study between three different slot/pole combinations for a five phase external rotor modular PM machine. The study shows that machine torque density and efficiency are enhanced as the number of rotor poles increases. However, this is at the expense of an increase in the DC-link voltage. The 20 slot/22 pole combination is found to be the best selection. However, better flux distribution and less core loss are reported for the 20 slot/14 pole combination. From a fault tolerant perspective, the performance of the three slot/pole selections is similar; however, the 20 slot/18 pole combination gives minimum torque ripple for both healthy and faulted cases. Analysis of the healthy and fault case is provided using a phase model approach developed to simulate the machine dynamics.

\section{References}

[1] J. Wang, K. Atallah, and D. Howe, "Optimal torque control of fault-tolerant permanent magnet brushless machines," IEEE Transactions on Magnetics, vol. 39, no. 5, pp. 2962-2964, 2003.

[2] B. C. Mecrow, A. G. Jack, J. A. Haylock, and J. Coles, "Fault tolerant permanent magnet machine drives," IEE Proceedings Electric Power Applications, vol. 143, no. 6, pp. 437-442, 1996.

[3] A. J. Mitcham, G. Antonopoulos, and J. J. A. Cullen, "Favourable slot and pole number combinations for faulttolerant PM machines," IEE Proceedings Electric Power Applications, vol. 151, no. 5, pp. 520-525, 2004.

[4] E. Levi, "Multiphase electric machines for variable-speed applications," IEEE Transactions on Industrial Electronics, vol. 55, no. 5, pp. 1893-1909, 2008.

[5] B. C. Mecrow, A. G. Jack, D. J. Atkinson et al., "Design and testing of a four-phase fault-tolerant permanent-magnet machine for an engine fuel pump," IEEE Transactions on Energy Conversion, vol. 19, no. 4, pp. 671-678, 2004.

[6] G. J. Atkinson, B. C. Mecrow, A. G. Jack, D. J. Atkinson, P. Sangha, and M. Benarous, "The analysis of losses in highpower fault-tolerant machines for aerospace applications," IEEE Transactions on Industry Applications, vol. 42, no. 5, pp. 1162-1170, 2006.

[7] K. Atallah, J. Wang, and D. Howe, "Torque-ripple minimization in modular permanent-magnet brushless machines," IEEE Transactions on Industry Applications, vol. 39, no. 6, pp. 1689-1695, 2003.

[8] S. Dwari, L. Parsa, and T. A. Lipo, "Optimum control of a fivephase integrated modular permanent magnet motor under normal and open-circuit fault conditions," in Proceedings of the IEEE 38th Annual Power Electronics Specialists Conference (PESC '07), pp. 1639-1644, June 2007.

[9] N. Bianchi, S. Bolognani, and M. Dai Pré, "Design and tests of a fault-tolerant five-phase permanent magnet motor," in Proceedings of the 37th IEEE Power Electronics Specialists Conference 2006 (PESC '06), pp. 1-8, June 2006.

[10] N. Bianchi and M. Dai Pré, "Use of the star of slots in designing fractional-slot single-layer synchronous motors," IEE Proceedings, vol. 153, no. 3, pp. 459-466, 2006.
[11] F. Scuiller, J. F. Charpentier, E. Semail, and S. Clénet, "Comparison of two 5-phase Permanent Magnet machine winding configurations. Application on naval propulsion specifications," in Proceedings of the IEEE International Electric Machines and Drives Conference (IEMDC '07), vol. 1, pp. 3439, May 2007.

[12] L. Parsa and H. A. Toliyat, "Five-phase permanent-magnet motor drives," IEEE Transactions on Industry Applications, vol. 41, no. 1, pp. 30-37, 2005.

[13] R. Wrobel, P. H. Mellor, N. McNeill, and D. A. Staton, "Thermal performance of an open-slot modular-wound machine with external rotor," IEEE Transactions on Energy Conversion, vol. 25, no. 2, pp. 403-411, 2010.

[14] J. R. Fu and T. A. Lipo, "Disturbance-free operation of a multiphase current-regulated motor drive with an opened phase," IEEE Transactions on Industry Applications, vol. 30, no. 5, pp. 1267-1274, 1994.

[15] A. M. El-Refaie and T. M. Jahns, "Optimal flux weakening in surface PM machines using concentrated windings," in Proceedings of the 39th Annual Meeting Industry Application Conference, vol. 2, pp. 1038-1047, October 2004.

[16] E. Chiricozzi and M. Villani, "Analysis of fault-tolerant fivephase IPM synchronous motor," in Proceedings of the IEEE International Symposium on Industrial Electronics (ISIE '08), pp. 759-763, July 2008.

[17] L. Parsa and H. A. Toliyat, "Fault-tolerant five-phase permanent magnet motor drives," in Proceedings of the 39th IEEE Industry Application, Annual Meeting, pp. 1048-1054, October 2004.

[18] N. Bianchi, S. Bolognani, and M. Dai Pré, "Strategies for the fault-tolerant current control of a five-phase permanentmagnet motor," IEEE Transactions on Industry Applications, vol. 43, no. 4, pp. 960-970, 2007. 

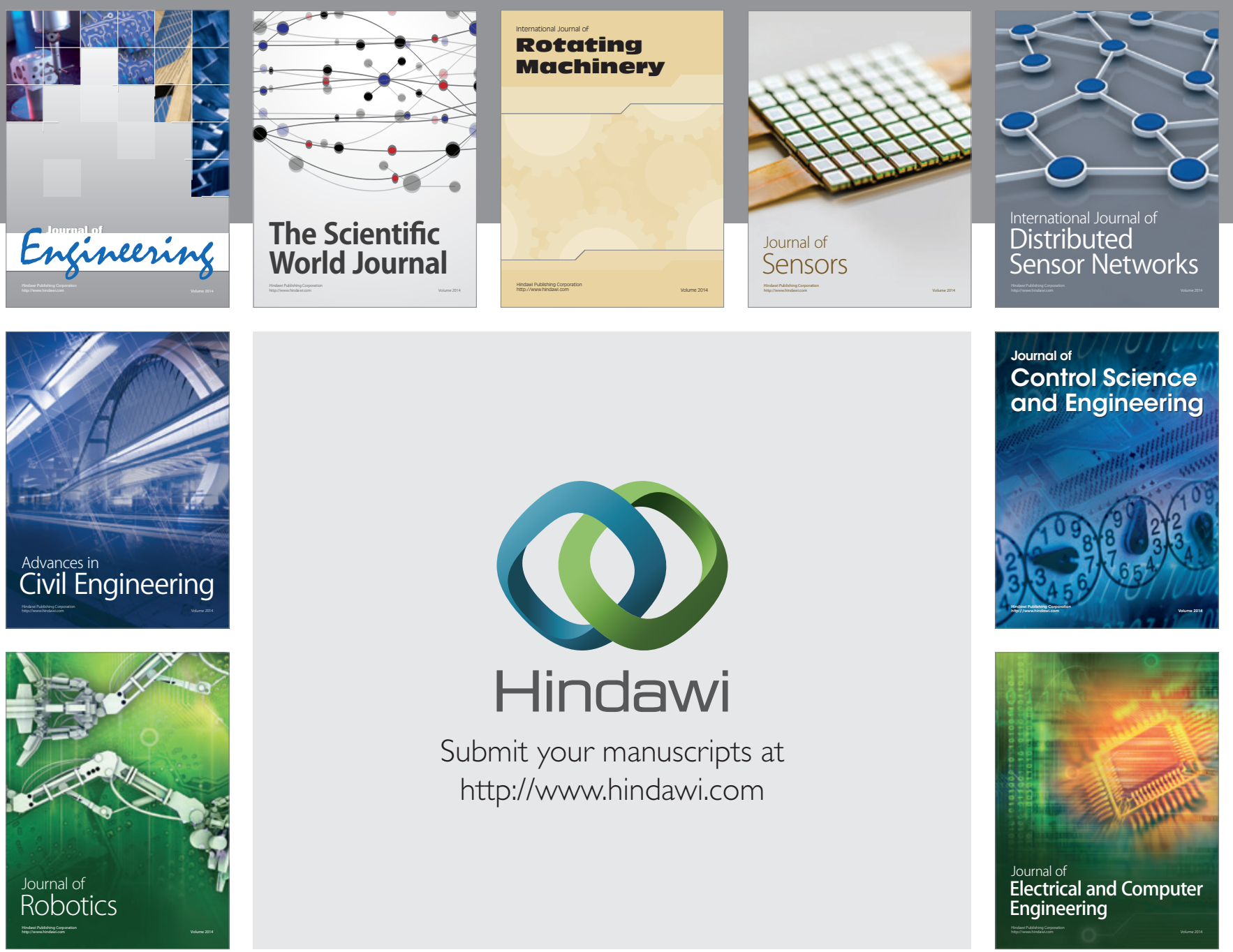

Submit your manuscripts at

http://www.hindawi.com
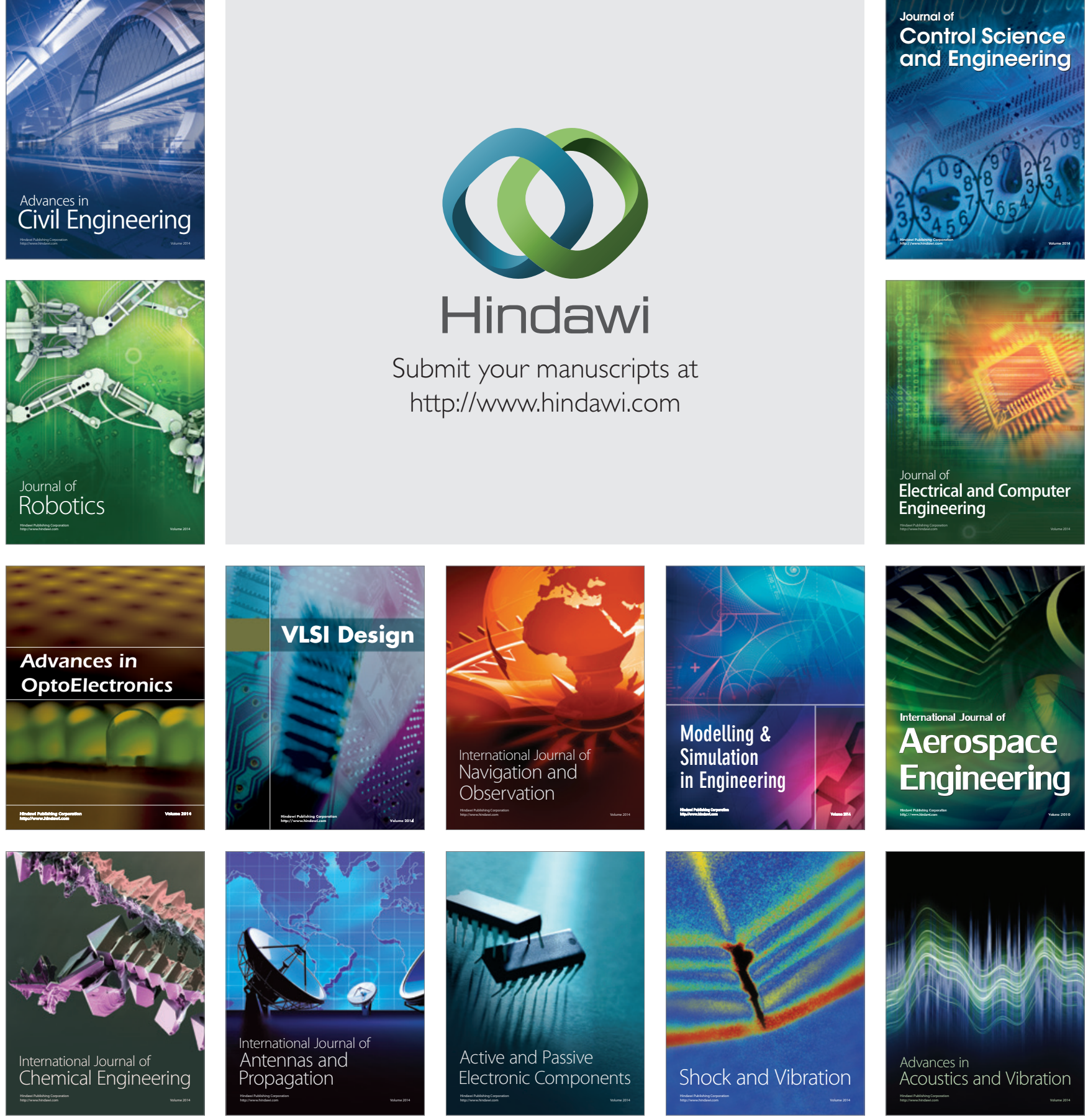